\title{
Sistema de Justiça, Função Social do Contrato e a Indenização do Dano Reflexo ou por Ricochete
}

\author{
Rafael Peteffi da Silva ${ }^{1}$
}

\begin{abstract}
Resumo: $\mathrm{O}$ artigo tem como objetivo inicial fixar a modelagem jurídica triangular típica dos danos reflexos ou por ricochete, visando diminuir a falta de clareza conceitual que o instituto apresenta. Em um segundo momento, o artigo analisa os desenvolvimentos doutrinários e jurisprudenciais relacionados com a norma contida no artigo 948 do Código Civil, pois o seu suporte fático consubstancia o chamado "caso clássico", por ser a única espécie de dano reflexo fartamente desenvolvida no cenário nacional. Após estabelecer os parâmetros indenizatórios relacionados com o artigo 948 do Código Civil, o artigo busca novas hipóteses de danos reflexos indenizáveis, principalmente pela conexão com um dos conteúdos eficacionais típicos do princípio da função social do contrato, que flexibiliza o princípio da relatividade dos efeitos contratuais.
\end{abstract}

Palavras-chave: Dano Reflexo. Código Civil. Função Social do Contrato.

\begin{abstract}
The article aims, initially, to set the typical triangular legal modeling of the reflex damage, aiming to reduce lack of conceptual clarity that the institute presents. In a second step, the article analyzes the doctrinal and jurisprudential developments related to the provision contained in art. 948 of the Civil Code, as its factual support constitutes the so-called "classic case" because it is the only kind of reflex damage widely developed on the national scene. After establishing the parameters related to severance art. 948 of the Civil Code, the article seeks new cases of compensable reflex damage, especially the connection to the content of the principle of the social function of the contract, which makes less strong the principle of privity of contract.
\end{abstract}

Keywords: Reflex Damage. Civil Code. Social Function of the Contract.

\section{Introdução}

Aquilo que em nosso país é chamado de dano reflexo ou por ricochete é uma categoria jurídica difundida em outros ordenamentos, sendo

1 Possui mestrado em Direito pela Universidade Federal do Rio Grande do Sul (2001) e Doutorado em Direito Civil pela Universidade de São Paulo - USP (2004). Professor adjunto da Universidade Federal de Santa Catarina. Professor da ESMESC. Diretor-geral da ESA/SC.E-mail: rpeteffi@terra.com.br.

Recebido em: 30/09/2011.

Revisado em: 27/10/2011.

Aprovado em: 30/10/2011. 
denominado de dommage par ricochet na França, danno riflesso na Itália e daño por rebote nos países de língua espanhola (GERALDES, 2007). Pode-se dizer que o próprio nome já fornece uma visão interessante do instituto do dano reflexo que, segundo o professor Fernando Noronha (2003, p. 578), é “[...] aquele que atinge outras pessoas, por estarem ligadas àquela que é vítima imediata de um determinado fato lesivo."

Geneviève Viney e Patrice Jourdain (2006, p. 154) explicam que

[...] é freqüente, principalmente em casos de acidente corporal, que os danos sofridos pela vítima imediata sejam eles mesmos a fonte de outros prejuízos, atingindo, por exemplo, as pessoas que se acham obrigadas a indenizar a vítima inicial ou aquelas que possuem com esta relações de interesse ou afeição que o evento danoso bruscamente perturbou.. ${ }^{2}$

É interessante notar a dificuldade de se encontrar conceitos operacionais claros - tanto na doutrina internacional como, muito particularmente, na doutrina brasileira - que consigam identificar os danos reflexos como categorias jurídicas autônomas e dotadas de um conteúdo eficacional próprio. Mesmo autores que dedicam obras monográficas sobre o assunto furtam-se a oferecer uma definição clara dos conceitos operacionais que utilizam ${ }^{3}$.

As lições sobre a matéria, de um modo geral, já iniciam por enfrentamentos casuísticos, cujo exemplo mais marcante é a indenização dos parentes da vítima de homicídio, tal como positivado no artigo 948 do Código Civil brasileiro.

Em nosso sentir, esse tipo de dano poderia ser explicado como o prejuízo que pode ser observado sempre em uma relação triangular em que o agente prejudica uma vítima direta que, em sua esfera jurí-

\footnotetext{
2 No original " Il est fréquent, notamment en cas d'accident corporel, que le dommage subi par le victim immediate soit lui-même la source d'outres préjudices, atteingnant, par exemple, les personnes qui se trouvent obligées d'indemniser la victime initiale ou celles qui entretenaient avec elle des rapports d'intéret ou d'affection que l'événement dommageable a brusquement perturbes."
}

3 Nesse sentido, GERALDES, 2007. 


\section{dica própria, sofre um prejuízo que resultará em um segundo dano, próprio e independente, observado na esfera jurídica da vítima refle- xa ou por ricochete.}

Atualmente, em nosso país, além da falta de conceitos bem assentados em nossa doutrina, nem mesmo um consenso mínimo sobre as espécies de dano reflexo indenizáveis parece existir ${ }^{4}$.

Como toda a observação do dano reflexo, no direito brasileiro e em grande parte do direito estrangeiro, principia pela análise das possibilidades indenizatórias extraídas direta ou indiretamente do chamado "caso clássico", ou seja, a norma contida no artigo 948 do Código Civil, o primeiro capítulo será dedicado ao estudo do atual posicionamento jurisprudencial e doutrinário sobre essa espécie, a fim de fornecer uma visão geral das hipóteses indenizatórias mais comuns.

Fora dos casos ordinários, as novas (ao menos para a doutrina nacional) possibilidades de flexibilização do princípio da relatividade dos efeitos contratuais, mormente com a positivação do princípio da função social do contrato pelo artigo 421 do novo Código Civil, revelaram uma ampla zona de conexão com as modalidades de inadimplemento contratual e o surgimento dos danos reflexos ou por ricochete. Nesse viés, pode-se estudar a possibilidade do inadimplemento contratual ter no dano reflexo ou por ricochete uma de suas principais consequências, bem como, simbioticamente, verificar se a aplicação do princípio da função social do contrato poderia atuar como um dos critérios para fixar do dano reflexo ou por ricochete dentro da moldura dos danos indenizáveis.

Aguçando a importância e a atualidade do debate, o Superior Tribunal de Justiça julgou recente caso de dano reflexo, pouco comum na jurisprudência pátria, analisando a sua compatibilidade com a responsabilidade contratual e com a responsabilidade aquiliana. Pelas razões expostas, o

\footnotetext{
4 Sergio Cavalieri Filho (2010) se manifesta, baseado na doutrina de Antunes Varela e acompanhando o entendimento do Direito Português, por uma restrição absoluta de dano reflexos patrimoniais além da hipótese do artigo 948 do Código Civil. Em sentido contrário, utilizando exemplos de dano patrimonial reflexo em relações de trabalho, tem-se SILVA (1997). O Ministro Paulo de Tarso Sanseverino também advoga por uma hipótese de dano patrimonial reflexo não contemplada pelo artigo 948 do Código Civil.
} 
segundo capítulo será dedicado ao estudo das relações entre a responsabilidade contratual, a função social do contrato e os danos reflexos.

\section{O Caso Clássico}

O presente capítulo visa traçar um perfil da indenização do dano reflexo ou por ricochete no direito brasileiro, o qual, apesar de comportar outros casos de dano reflexo ou por ricochete ${ }^{5}$, costuma centrar o debate na hipótese positivada no artigo 948 do Código Civil pátrio. Efetuam-se comparações, quando possível, com o desenvolvimento desses mesmos danos no direito estrangeiro.

Destarte, o artigo 948 do Código Civil de $2002^{6}$, que praticamente repete o artigo 1.537 do Código Civil de 1916, garante a indenização pelos danos reflexos, autônomos e independentes, sofridos por algumas pessoas determinadas, em geral pessoas muito próximas ao falecido, em caso de homicídio. Lembre-se que o legislador do novo Código Civil incluiu, ao final do caput do artigo 948, a expressão "sem excluir outras reparações", conferindo abertura sistemática ao modelo de indenização brasileiro e explicitamente libertando a jurisprudência para aumentar o catálogo de danos indenizáveis.

Vale ressaltar que a indenização devida aos próximos da vítima em caso de homicídio é também um caso clássico em ordenamentos alienígenas, como ocorre na França e na Itália, que não possuem um artigo específico sobre a espécie, e na Alemanha e em Portugal, que contam com dispositivos legais que conferem explicitamente a possibilidade de se requerer os danos por ricochete (SANSEVERINO, 2010; PORTO, 1996) em caso de homicídio.

5 O presente trabalho não se ocupará da análise de outras espécies de dano reflexo no direito brasileiro, o que poderá ser feito em trabalho futuro, limitando-se a centrar a análise nas conexões com o "caso clássico" e com hipóteses de inadimplemento contratual.

6 Art. 948. No caso de homicídio, a indenização consiste, sem excluir outras reparações: I - No pagamento das despesas com o tratamento da vítima, seu funeral e o luto da família;

II - Na prestação de alimentos às pessoas a quem o morto os devia, levando-se em conta a duração provável da vida da vítima [...] 
A força da positivação legal explícita conferida pelo artigo citado foi capaz de garantir solidez jurisprudencial e doutrinária para essa hipótese específica de dano reflexo ou por ricochete, permitindo somente algumas controvérsias sobre a quantificação das verbas indenizatórias. Para uma correta noção dos danos que o ordenamento brasileiro costuma admitir, baseado no artigo 948, serão divididos os danos reflexos com efeito patrimonial dos danos reflexos com efeitos extrapatrimoniais.

\subsection{Danos Patrimoniais}

Pode-se dizer que, em relação às verbas contidas no inciso I do artigo 948, observa-se grande coesão jurisprudencial e doutrinária no direito pátrio. Em relação às despesas de funeral, a jurisprudência costuma conceder a indenização suficiente para custear um funeral digno (caixão, flores, compra de espaço para a colocação do cadáver, etc..), observando a condição social do morto e os usos e costumes do local do seu domicílio, para aquilatar o grau de sofisticação que os procedimentos funerários deverão seguir (MONTENEGRO, 2005). É interessante notar que a França, um dos países mais progressistas na indenização de danos reflexos ou por ricochete (VINEY; JOURDAIN, 2006), somente permite a reparação pelas despesas de funeral em casos excepcionais, já que essa despesa teria de ser obrigatoriamente custeada pelos parentes em algum momento, independentemente do fato ilícito do agente causador dano (LE TOURNE$\mathrm{AU}$; CADIET, 1998) ${ }^{7}$, pois a morte é um fato que inexoravelmente irá ocorrer.

Os custos com o tratamento da vítima também não costumam ensejar grandes dificuldades para a quantificação, pois estão adstritos às despesas médicas, hospitalares, de transporte e outras necessárias na tentativa de salvação da vítima (MONTENEGRO, 2005; SANSEVERINO, 2010).

O luto da família já foi considerado por alguns autores, como Carvalho Santos, um conceito amplo o suficiente para a indenização de uma parcela de danos morais, principalmente em uma época em que esse tipo

7 Os autores falam que apenas custos como as despesas de viagem dos parentes ou de translado do corpo em caso de morte fora do domicílio do de cujus. No mesmo sentido, SANSEVERINO, 2010, p. 208. 
de dano tinha a sua aceitação muito dificultada. Atualmente, as verbas concedidas pelo luto da família consistem, eventualmente, na vestimenta apropriada para o funeral e, sobretudo, na chamada licença nojo, que é o lapso temporal necessário para que os parentes próximos da vítima se recuperem minimamente do grave choque emocional sofrido e voltem a exercer atividade produtiva. São danos exclusivamente patrimoniais, portanto.

Os funcionários públicos ou celetistas não fazem jus a essa verba, pois já tem a garantia de um período de licença remunerada para esse fim; já os trabalhadores autônomos ou profissionais liberais estão legitimados para requerer os lucros cessantes do período de inatividade, que normalmente deve ser de uma semana, mas pode ser aumentado em casos excepcionais, como na morte inesperada e violenta de um jovem, trazendo trauma profundo para os seus pais (SANSEVERINO, 2010, p. 211-212).

O artigo 948 II garante o meio de subsistência básico para as vítimas reflexas ou por ricochete quando da morte da pessoa que garantia o seu sustento. $\mathrm{O}$ pensionamento garantido pela norma legal é limitado às vítimas que possuíam a condição jurídica de requisitar alimentos para o de cujus, necessitando, adicionalmente, demonstrar a dependência econômica, v.g., os pais de boa condição financeira de um filho de meia idade, falecido, que também trabalhava, não farão jus à verba consignada no artigo 948 II.

Cessada a dependência econômica, cessará o pensionamento. É o que acontece no caso do filho menor ao completar 18 anos, a não ser em caso de estar cursando ensino superior, fato que levou a jurisprudência a alongar o tempo de pensionamento até os 24 anos (MONTENEGRO, 2005; SANSEVERINO, 2010).

Paulo de Tarso Sanseverino (2010, p. 216) coloca, com acerto, que o rol de legitimados para requerer a indenização do artigo 948 II deveria ser aumentado, conforme vem ocorrendo na França, onde foi conferida a proteção para a concubina,

Finalmente, com fundamento nas funções compensatórias e concretizadora do princípio da reparação integral, pode-se flexibilizar a vinculação jurídica para a concessão de pensão por morte em be- 
nefício de pessoas a quem a pessoa morta, por um vínculo fático, prestava alimentos. São hipóteses do enteado da união estável ou da criança colocada em família substituta sem as formalidades do ECA, economicamente dependentes do falecido, mas sem vínculo jurídico, que são situações bastante comuns na sociedade brasileira. ${ }^{8}$

Apesar do artigo 948 do Código Civil não fazer menção expressa aos prejuízos extrapatrimoniais, eles também são indenizados pelo ordenamento brasileiro na hipótese do "caso clássico".

\subsection{Danos Extrapatrimoniais}

Em relação aos danos extrapatrimoniais, o comentado "caso clássico" também é fonte de interessantes danos reflexos. Destarte, indene de dúvidas que as pessoas próximas do falecido sofrem um dos piores abalos psicológicos que o ser humano pode experienciar. A despeito dessa profunda dor, o Supremo Tribunal Federal em muito relutou para admitir a reparação para os parentes próximos da vítima.

Luiz Renato Ferreira da Silva bem lembra que essa relutância era decorrência lógica da negativa de indenização do dano moral cumulado com o dano patrimonial, que outrora era a regra básica de jurisprudência dominante no STF (SILVA, 1997). Paulo de Tarso Sanseverino também recorda que a falta de abertura sistemática do artigo 1.537 do Código Civil de 1916, bem como a ausência de uma referência expressa aos danos

\footnotetext{
8 Apesar de apenas trabalhar com o exemplo dos alimentos devidos por um companheiro ao outro em casos de uniões conjugais de fato (a união estável para o ordenamento nacional), Gerales (2007, p. 20) contribui para o debate, utilizando categoria de credores de obrigação natural para definir os legitimados a requerer a pensão por morte. Nesse sentido, as palavras do autor português, "Mas o legislador não atentou apenas nas situações que envolvem uma obrigação legal de alimentos. Foi ao ponto de tutelar ainda os terceiros beneficiários de prestações alimentícias concedidas pela vítima, não como efeito do cumprimento de um dever legal de alimentos, mas como decorrência de uma mera obrigação natural. As obrigações naturais são caracterizadas essencialmente pela sua inexigibilidade, nos termos do art. 402, encontrando o seu fundamento em meros deveres de ordem moral ou social. Por isso, o seu cumprimento não decorre de uma imposição legal, antes resulta da assunção espontânea de um dever de justiça."
} 
extrapatrimoniais, tiveram papel importante para uma grande dificuldade inicial (SANSEVERINO, 2010).

Entretanto, as últimas décadas já observaram uma jurisprudência nacional bastante sólida em relação à reparação do chamado prejudice d'affection sofrido pelos próximos do falecido, fazendo com que esse tipo de indenização também já possa ser chamada de clássica.

Há unanimidade entre a doutrina nacional e estrangeira em reconhecer que estabelecer o rol de legitimados para requerer esse tipo de indenização é uma tarefa extremamente complexa, sendo que o direito estrangeiro possui soluções puramente jurisprudenciais, como ocorre com a França, que acabou se constituindo em grande paradigma comparativo para o ordenamento pátrio, e soluções baseadas em dispositivos legislativos, como ocorre em Portugal, que conta com um rígido rol taxativo de legitimados para requerer indenização por dano extrapatrimonial surgido pelo homicídio de terceiro. O artigo 496 do Código Civil Português assim prescreve,

Art. 496 (Danos não patrimoniais)

1. Na fixação da indenização deve atender-se aos danos não patrimoniais que, pela sua gravidade, mereçam a tutela do direito.

2. Por morte da vítima, o direito à indenização por danos não patrimoniais cabe, em conjunto, ao cônjuge não separado judicialmente de pessoas e bens e aos filhos ou outros descendentes; na falta destes, aos pais ou outros ascendentes; e, por último, aos irmãos ou sobrinhos que os representem.

3. O montante da indemnização será fixado equitativamente pelo tribunal, tendo em atenção, em qualquer caso, as circunstâncias referidas no artigo 494. ${ }^{\circ}$; no caso de morte, podem ser atendidos não só os danos não patrimoniais sofridos pela vítima, como os sofridos pelas pessoas com direito a indemnização nos termos do número anterior.

Atualmente, pode-se dizer que há, fixado pela jurisprudência brasileira, uma presunção juris tantum em favor dos pais, cônjuge ou companheiro e filhos do de cujus (SILVA, 1997; SANSEVERINO, 2010), sendo 
que outras pessoas, como irmãos e sobrinhos, também podem ser incluídos, em situações especiais ${ }^{9}$.

Certamente, o cerne do presente trabalho não é expor com aprofundado detalhamento todos os debates em torno do "caso clássico" de dano por ricochete em nosso ordenamento, até porque já existem trabalhos de grande qualidade e atualidade nessa área ${ }^{10}$. Entretanto, a breve exposição realizada será importante para traçar alguns paralelos com outras hipóteses de danos reflexos ou por ricochete que serão tratados a seguir, na tentativa de se desenhar um mapa geral da possibilidade indenizatória desse tipo de prejuízo no Direito Brasileiro, quando relacionado com o inadimplemento contratual.

\section{Função Social do Contrato, Responsabilidade Contratual e Novas Possibilidades de Dano por Ricochete}

Inicialmente, não nos parece trazer maiores dificuldades a constatação de que os danos reflexos podem ser incluídos entre aqueles danos observados como consequência do inadimplemento contratual.

Mesmo o dano reflexo sentido pelos parentes próximos de uma pessoa falecida, denominado por nós como "caso clássico", não se mostra refratário a relações com a seara contratual, para isto basta lembrar a hipótese em que a vítima direta tenha falecido por obra de um erro médico, isto é, do inadimplemento do contrato de prestação de serviços médicos ${ }^{11}$. $\mathrm{O}$ inadimplemento do contrato de trabalho também pode se mostrar apto

9 Nesse sentido, recente julgado do STJ (REsp. n. 1124471/RJ, rel. Min. Luiz Fux, Primeira Turma, j. em 17-6-2010). Note-se que o presente julgado também enfrenta a questão da pensão mensal aos dependentes.

12. In casu, a vítima, contava com 28 anos de idade, por isso que, utilizando-se a expectativa de sobrevida da tabela do IBGE, para a época dos fatos, que era de 47,4 anos, alcança-se a idade de 75,4 anos, limite para a fixação do pensionamento concedido aos autores da ação.

13. Recurso Especial parcialmente provido.

10 Exemplificativamente ver SANSEVERINO, 2010 e MONTENEGRO, 2005.

11 Garantindo a natureza preponderantemente contratual da responsabilidade médica tem-se KFOURI NETO, 2007. 
a preencher o suporte fático do artigo 948 do Código Civil, nos casos em que há morte do funcionário durante sua atividade laboral.

Estabelecido esse ponto inicial, mister apresentar uma proposta de taxionomia para tratar o tema. Destarte, como todos os exemplos de danos reflexos ou por ricochete pressupõem uma relação triangular, já apresentada na introdução do presente estudo (agente, vítima direta e vítima indireta), pode-se imaginar o inadimplemento ocorrendo em distintas situações.

Em primeiro lugar observa-se o dano reflexo nas hipóteses em que o inadimplemento contratual imputável existir entre vítima direta e agente causador do dano, como no exemplo do acidente fatal ocorrido por descumprimento do contrato de trabalho, em que o empregador (agente) não forneceu a segurança essencial ao mister do trabalhador (vítima direta) ${ }^{12}$. Outra possibilidade pode ser verificada quando o inadimplemento ocorre entre vítima direta (devedor) e vítima indireta (credor), sendo o causador do inadimplemento um terceiro não pertencente à relação contratual ${ }^{13}$.

\subsection{O Terceiro como Vítima Indireta, Decorrente do Inadimplemento entre Devedor e Vítima Direta}

Os exemplos de "casos clássicos” já verificados enquadram-se na primeira hipótese aludida, isto é, quando o devedor é o causador do dano e a vítima indireta é estranha à relação contratual.

Apesar dessa inicial facilidade de tratamento, já que se mencionou as hipóteses de inadimplemento contratual que se encaixam perfeitamente no já citado "caso clássico", expressamente albergado legislativamente

12 Nesse sentido, trabalhando alguns acórdãos julgados pela Justiça do Trabalho, SCHIAVI, 2008. Do Tribunal de Justiça catarinense extrai-se, TJSC, ap. cível n. 2008.021946-9, j. 27/02/2009.

13 Essa classificação em dois grandes blocos também é observada na taxionomia proposta por alguns autores quando da análise das possíveis aplicações do princípio da função social do contrato como flexibilizador do princípio da relatividade dos efeitos contratuais. Nesse sentido NEGREIROS, 2002, que aponta que a função social pode ter sua eficácia sentida quando (i) o terceiro é prejudicado pelo descumprimento de uma obrigação contratual e (ii) quando o credor é prejudicado pelo comportamento do terceiro. 
pelo artigo 948 do Código Civil, análises mais complexas sobre a ressarcibilidade dos danos reflexos vinculados a alguns tipos de inadimplemento podem ser observadas, principalmente quando se enfrentam questões relativas a algumas eficácias do princípio da função social dos contratos. Com efeito, além dos casos albergados expressamente por disposição normativa específica (artigo 948), necessita-se da força trazida pela renovada principiologia contratual para empreender novas análises, pois, como bem relata Teresa Negreiros (2002, p. 230),

[...] no tocante à definição da posição do "terceiro vítima", a interpretação clássica do princípio da relatividade nega-lhe legitimidade para pleitear indenização frente ao devedor inadimplente.

Destarte, a relatividade dos efeitos contratuais é princípio tradicional e fundamental para a teoria geral dos contratos. É exatamente por efeito deste princípio que a doutrina clássica acabou por efetuar uma separação bastante nítida entre duas categorias do direito contratual: partes e terceiros. Note-se que o princípio da relatividade dos efeitos contratuais teve papel fundamental na teoria moderna do contrato e mostra-se, ainda, basilar ${ }^{14}$.

14 Ver RODRIGUES JÚNIOR, 2004. Nesse sentido se manifesta o autor, "Entrementes, é indispensável afastar uma espécie de posição pseudocientífica sobre os institutos e princípios do direito tradicional, quase sempre criticados pelo simples fato de sua antigüidade, num exercício estéril e reducionista de contraposição entre o velho e o novo, colocando-se este sempre em preeminência sobre aquele, sob o frívolo argumento de que as rerum novarum são, por si mesmas, melhores que as coisas do passado. De fato, a noção de que res inter alios acta tertiis nec prodest nec nocet, não se pode desconhecer, também sintetiza a lenta evolução de conceitos extremamente éticos e humanísticos em torno da responsabilidade individual e da intransferibilidade de direitos e sanções. Clóvis Beviláqua (1977:42-43), esforçado em antropólogos e historiadores, preleciona que durante muito tempo as penas por atos ilícitos - cíveis ou não - eram expiadas por todo o grupo a que pertencia o infrator, independentemente dos demais membros haverem concorrido para o dano. A inadimplência de um indivíduo poderia repercutir sobre os demais integrantes da família, da tribo ou da cidade, numa odiosa extensão dos efeitos a terceiros. Miguel Maria de Serpa Lopes (1991:109), situando adequadamente o princípio da relatividade dos efeitos sob a óptica do Setecentos e do Oitocentos, preleciona que seu fundamento maior era a liberdade humana e que, visando protegê-la, firmou-se a ideia de que os contratos não podem ter eficácia além das próprias partes que neles consentiram. 
Entretanto, a eficácia das relações obrigacionais perante terceiros há muito vem ocupando a mente dos juristas mais perspicazes (AZEVEDO, 2000) e, no Brasil, obteve inegável impulso com a promulgação do novo Código Civil, que positivou, de forma explícita, o princípio da função social do contrato.

Esse princípio contratual foi, desde as primeiras análises do novo diploma civil, intimamente relacionado com todas as possibilidades de tutela externa do crédito $^{15}$. Nesse sentido, o enunciado 21, aprovado na I Jornada de Direito Civil, patrocinada pelo Conselho da Justiça Federal, assim preceitua

21 - Art. 421: a função social do contrato, prevista no art. 421 do novo Código Civil, constitui cláusula geral, a impor a revisão do princípio da relatividade dos efeitos do contrato em relação a terceiros, implicando a tutela externa do crédito [...]

Em primeiro lugar, cumpre identificar algumas hipóteses específicas de utilização da eficácia contratual estendida a terceiros, a fim de verificar se existe real vinculação com a categoria dos danos reflexos ou por ricochete. Mantendo-nos ainda circunscritos à primeira categoria antes estudada, ou seja, àquela vinculada aos "casos clássicos", em que a vítima indireta é estranha ao contrato firmado entre vítima direta e agente causador do dano, cumpre analisar outras espécies em que o credor do contrato sofreria um dano que acaba por refletir em uma segunda vítima, que vem a sofrer o dano reflexo. ${ }^{16}$

Uma hipótese de eficácia externa do crédito que vem sendo desenvolvida pela nossa doutrina e jurisprudência ocorre quando se confere le-

Considere-se, então, que o desenvolvimento do princípio da relatividade dos efeitos do contrato marcou um sensível avanço na História do Direito, representando a afirmação de indicações de elevado conteúdo moral e notória eticidade, além de preservar a segurança jurídica."

15 Nesse sentido, MARTINS-COSTA, 2005.

16 Parece que GAMARRA, 2000, p. 296 também concorda que o caso clássico do pensionamento poderia ser considerado como uma espécie de extensão dos efeitos dos contratos para terceiros. 
gitimidade ativa para a vítima entrar com ação direta, em caso de acidente, contra a seguradora privada que havia segurado o veículo do agente culpado, por intermédio de contrato de seguro facultativo ${ }^{17}$.

Vale lembrar que o citado caso não obedece ao esquema triangular dos danos reflexos, pois o inadimplemento por parte do devedor (seguradora) não chegou a causar um dano para o credor do contrato de seguro (agente culpado pelo acidente), pois este acabou por não pagar nada para a vítima, tanto que a ação direta fez-se necessária. Assim, não há a figura do dano direto, essencial na modelagem triangular defendida neste traba1 ho ${ }^{18}$. Caso o dano fosse realmente sofrido pelo segurado (vítima direta), tendo que pagar a indenização devida à vítima, seria ele o único legitimado a ajuizar ação de cobrança contra a seguradora, eliminando, também nessa hipótese, a visualização da categoria de danos reflexos ou por ricochete.

O autor, Antonio Santos Abrantes Geraldes, tenta relacionar alguns casos de tutela externa do crédito com o tema de nosso trabalho, citando o caso do direito consumerista português, em que um consumidor pode requerer a responsabilidade de um produtor com quem nunca celebrou contrato, ou o caso da ação pauliana, em que um terceiro pode requerer a ineficácia de um contrato feito entre as partes (GERALDES, 2007). Entretanto, parece que os exemplos encontrados no autor de monografia específica sobre os danos reflexos também não seguem a configuração adotada, que necessita de uma vítima direta, sofrendo um dano próprio e independente e uma vítima reflexa, sofrendo outro dano, também próprio e independente em relação ao dano sofrido pela vítima direta. É verdade que ambos os exemplos estão conectados com a flexibilização do princípio da relatividade dos efeitos contratuais, mas no caso do direito consumerista, o consumidor é a própria vítima direta, enquanto que no caso da ação pauliana a causa do dano sofrido pelo terceiro prejudicado pelo negócio jurídico celebrado entre as partes não é nenhum dano direto so-

17 NEGREIROS, 2002, com aprofundada análise da espécie jurisprudencial.

$18 \mathrm{O}$ caso não é tratado pelo viés da tutela indenizatória, pois o pedido da vítima é para poder ser incluído no polo ativo da ação de cobrança contra a seguradora, ou seja, aqui trata-se da ampliação da eficácia do contrato para permitir que o terceiro exija, judicialmente, o cumprimento contratual. 
frido por uma delas, mas exatamente o negócio jurídico por elas voluntariamente celebrado. Assim, nem o consumidor lesado, tampouco o terceiro lesado por negócio jurídico alheio podem ser considerados verdadeiras vítimas indiretas.

Portanto, parece não haver maior vinculação entre os casos aqui analisados (excetuando-se os "casos clássicos"), relacionados com a flexibilização do princípio da relatividade dos efeitos contratuais, e a categoria dos danos reflexos ou por ricochete.

\subsection{Terceiro Responsável por Causar o Inadimplemento do Vínculo Contratual entre Vítima Direta e Vítima Indireta}

Enfrentando agora a modalidade de eficácia externa dos contratos em que um terceiro é o responsável por causar o inadimplemento de vínculo contratual entre vítima direta e vítima indireta, também se nota as hipóteses que guardam relação com os danos reflexos e outras que se afastam da modelagem dessa categoria.

Com efeito, uma das espécies mais conhecidas da modalidade que agora analisa-se é denominada de teoria do terceiro cúmplice, em que se admite a possibilidade de se responsabilizar terceiro por ter interferido maliciosamente em um contrato alheio (MARTINS-COSTA, 2005).

Essa teoria foi trazida para o direito brasileiro pelo professor Antonio Junqueira de Azevedo (1998), quando comentou a possibilidade de uma fornecedora de combustível ser responsabilizada por vender para postos de combustíveis que possuíam contrato de exclusividade com outras distribuidoras.

Otavio Luiz Rodrigues Júnior (2004) explica a teoria citada

[...] numa perspectiva mais objetiva, é possível sinalar o problema da interferência - muitas vezes informal - do terceiro em um contrato, visando a impedir-lhe a execução plena ou até mesmo provocando sua extinção normal. $\mathrm{O}$ papel do terceiro, que atua nas sombras, de modo não-ostensivo, mas assegurando uma rede de proteção ao contraente seduzido, é que está a necessitar uma corre- 
ta qualificação jurídica, o que se torna possível mediante o uso da doutrina do terceiro cúmplice.

A própria legislação brasileira já positivou e ainda positiva alguns casos de punição ao terceiro que intervém ilicitamente em contrato alheio: o artigo 1.235 do Código Civil de Beviláqua e o artigo 608 do novo Código Civil, assim prescrevem,

Art. 1.235. Aquele que aliciar pessoas obrigadas a outrem por locação de serviços agrícolas, haja ou não instrumento deste contrato, pagará em dobro ao locatário prejudicado a importância, que ao locador, pelo ajuste desfeito, houvesse de caber durante quatro anos.

Art. 608. Aquele que aliciar pessoas obrigadas em contrato escrito a prestar serviço a outrem pagará a este a importância que ao prestador de serviço, pelo ajuste desfeito, houvesse de caber durante dois anos.

Mas note-se que em nenhum desses casos parece estar presente a estrutura básica dos danos reflexos ou por ricochete, pois não houve um dano a uma vítima direta que, em decorrência, lesou uma segunda vítima, por um prejuízo próprio e independente. Nas hipóteses da teoria do terceiro cúmplice analisadas, o devedor parece também estar se beneficiando da interferência, não sofrendo qualquer tipo de dano.

Jorge Gamarra (2000) sublinha que mesmo o direito francês, que se manteve extremamente focado na teoria do terceiro cúmplice para caracterizar a flexibilização do princípio da relatividade dos efeitos contratuais, chegou a admitir hipóteses em que um terceiro é o responsável por causar o inadimplemento de um contrato, deteriorando ou impossibilitando o recebimento de algum bem jurídico que o credor almejava receber, mas sem atuar em conjunto com o devedor, como ocorre na teoria do terceiro cúmplice ${ }^{19}$.

19 Nesse sentido, as palavras do autor "El segundo ejemplo que acaba de mencionarse (incêndio de la cosa arrendada) ya ofrece otra hipótesis distinta, de perjuicio del derecho de crédito, donde el comportamiento (doloso o culposo) del tercero daña la cosa, cuyo goce había concedido el arrendador al arrendatário. Um mismo acto daba lugar, entonces, a varias lesiones, creando uma pluralidad de damnificados; por un lado, daño al derecho 
O mestre uruguaio trabalha com a hipótese de um terceiro que provoca um incêndio em um galpão arrendado, lesando o direito de propriedade do arrendante (devedor) e o direito de crédito do arrendatário (credor e vítima indireta). Ainda lembra-se de um julgado que foi absolutamente fundamental para a jurisprudência italiana e francesa, decidido na década de 50, quando o famoso desastre de Superga vitimou, em um desastre aéreo, todo o time de futebol da agremiação do Torino, que intentou demanda de reparação contra a companhia aérea.

No mesmo passo, na França, a Corte de Apelação de Colmar condenou, em 1955, o responsável pela morte de um famoso jogador de futebol do Clube de Metz, pelos enormes danos que a morte do habilidoso jogador causara à equipe, no que foi elogiada por um comentário da lavra de René Savatier (GAMARRA, 2000, p. 291). Já a jurisprudência italiana teve outro posicionamento: agarrada à ideia clássica de que o crédito (contrato de trabalho entre jogador e agremiação) carecia de tutela aquiliana, decidiu que o clube não poderia receber qualquer indenização pelos danos sofridos no desastre mencionado.

Na década de 1970, a Corte de Cassação italiana teve oportunidade de rever o entendimento jurisprudencial do país, quando, coincidentemente, julgou outra demanda proposta pela agremiação do Torino, que havia perdido o habilidoso jogador "Meroni" em um acidente de automóvel. Aqui, a Corte teve oportunidade de conceder a reparação pretendida pela agremiação esportiva (GAMARRA, 2000) ${ }^{20}$.

de propriedade, que no planteaba dificultad alguna, siendo el caso tradicional de la responsabilidad aquiliana; por outro, la lesón del crédito, a través del daño a la cosa, cuyo goce el deudor-propietario se había obligado a procurar al acreedor, señalaba que la categoria de la lesión del crédito por parte de un tercero era más vasta que la mera complicidad en el incumplimiento."

${ }^{20}$ RODRIGUEZ JÚNIOR, 2004, faz interessante relato dos casos italianos, informando que uma parte da doutrina italiana identifica esses casos com a teoria do terceiro cúmplice, "Com efeito, toda a equipe de futebol do Torino, famoso clube italiano - composta por jogadores de grande prestígio como Mazzola, Loik e Gabetto -, desapareceu aos 04.05.1949, quando o avião foi sinistrado em um dramático acidente aeronáutico, chocando-se contra a colina de Superga, uma simpática cidade, com uma igreja dedicada à Nossa Senhora. Além da comoção nacional e familiar ante a morte dos atletas, surgiu um grave problema jurídico: "o time havia firmado diversos contratos publicitários em 
Entretanto, apesar do caso da década de 1950, Geneviéve Viney e Patrice Jourdain afirmam que a jurisprudência francesa tem se mostrado bastante rigorosa em casos de vítimas por ricochete na situação de credores, sócios e empregadores de vítimas diretas. Nesse sentido foi o julgado que impediu uma sociedade de requerer danos por ricochete causados em decorrência dos danos diretos sofridos por um dos sócios, no caso um sequestro. Entretanto, pode-se verificar casos como o de um médico que auferiu indenização pelo dano por ricochete ocasionado pela morte da esposa que lhe ajudava no consultório, devendo, depois de sua morte, contratar um profissional assalariado ou a espécie em que os empregados de um salão de beleza perderam seus empregos por causa da morte do proprietário, ocasionada por um motorista descuidado.

Portanto, não se pode dizer que a jurisprudência francesa é totalmente favorável a esse tipo de indenização por extensão da eficácia contratual a terceiros (VINEY; JOURDAIN, 2006).

Interessante notar que nos últimos casos analisados, isto é, as hipóteses em que a vítima indireta sofreu prejuízos em decorrência do inadimplemento, motivado por ação ou omissão de terceiro, de um contrato que possuía com a vítima direta, o terceiro pode ter descumprido um dever absoluto (ilícito absoluto), como ocorre no caso do acidente de automóvel, em que a vítima direta pediria reparação baseada na responsabilidade

função de futuras partidas, que ficaram sem possibilidade de execução pela superveniente morte dos jogadores". É evidente que tais pactos seriam resolvidos, segundo as regras da impossibilidade fisica superveniente, porém os prejudicados entenderam que a solução tradicional não os aliviaria dos inesperados e desproporcionais danos, além de exonerar a responsabilidade da companhia aérea, que, de algum modo, haveria dado causa a tais infortúnios, sem falar no problema atinente às coberturas securitárias, que não alcançavam os aludidos contratos publicitários e os campeonatos a serem disputados (REDENTI, 1951:49-56; GRECO, 1951:422-435). A Corte de Cassação italiana, à época, não admitiu a doutrina do terceiro cúmplice, o que só veio a ocorrer mais de vinte anos depois, em 1971, com o desastre automobilístico que vitimou o jogador Luigi Meroni, que, numa ironia do destino, também integrava o time de futebol do Torino (CASS. Sez. un. 26.01.1971 n. 174, in Foro it. 1971, I, 342 e 1284). O caso Meroni é reconhecido pelos autores peninsulares como o responsável por um autêntico giro copernicano na responsabilidade do terceiro em face de relações jurídicas envolvendo outras pessoas, marcando o ingresso definitivo da doutrina do terceiro cúmplice no âmbito das grandes questões do moderno direito civil (CIAN, 1971:199; SANTUOSOSSO, 1971:201). 
civil extracontratual ${ }^{21}$, como pode ter gerado o prejuízo à vítima direta por inadimplemento contratual (ilícito relativo), como no exemplo do acidente aeroviário, em que a companhia aérea inadimpliu o contrato de transporte.

No direito brasileiro, não há sistematização jurisprudencial das hipóteses de dano reflexo aludidas, tampouco aprofundamento doutrinário. Entretanto, pode-se identificar alguns exemplos doutrinários e alguns casos jurisprudências que parecem permitir que danos reflexos que surjam das hipóteses suprarreferidas sejam indenizados.

Luiz Renato Ferreira da Silva (1997, p. 192) aponta, mesmo sem confirmar a possibilidade de se indenizar esse tipo de dano no ordenamento brasileiro, interessante exemplo,

Pode-se, quiçá, vislumbrar melhor a titularidade autônoma do dano por ricochete com um exemplo desta modalidade no campo patrimonial. O empregador que vê seu empregado atropelado por um automóvel e fica sem que o mesmo possa prestar serviço por uma série de dias, embora não tenha sido a vítima do acidente, acaba, reflexamente, sendo atingido e enfrenta uma perda patrimonial, que, na linha de causalidade adequada, conduz ao autor do dano. O que resta atingido é o patrimônio do empregador, ainda que não tenha sido o alvo imediato da ofensa. É o seu lucro que ele quer repor com uma eventual indenização. $\mathrm{O}$ dano que ele sofre teria a natureza de dano por ricochete. (grifos nossos)

Interessantíssimo julgado foi decidido pelo Superior Tribunal de Justiça, em 201022, em que uma empresa de produções artísticas celebrou contrato com um maestro russo, no intuito de produzir alguns espetáculos artísticos em território nacional. Durante a viagem para o Brasil, a empresa aérea extraviou a bagagem do maestro, que não pode se apresentar,

21 Para ilustrar essa hipótese basta imaginar que o aludido jogador Meroni, ao invés de ter falecido no acidente automobilístico, tivesse ficado tetraplégico, impossibilitando a atividade desportiva que até então praticava.

${ }^{22}$ BRASIL. Superior Tribunal de Justiça. Recurso Especial n. 753.512 - RJ. Recorrente: Compagnie Nationale Air France. Recorrido: Dell'arte Promoções Artísticas LTDA. Relator para acórdão: Ministro Luis Felipe Salomão, julgado em 2 de março de 2010. 
pois não contava com suas partituras e outros materiais essenciais que estavam na bagagem extraviada.

A empresa ajuizou ação indenizatória contra a companhia aérea, tendo como um dos fundamentos o artigo 17 do Código de Defesa do Consumidor. $\mathrm{O}$ voto do Ministro relator entendeu pela improcedência da demanda, tendo em vista que o caso em tela estava relacionado com vício do serviço, declarando a inaplicabilidade do artigo 17 do CDC para essa categoria jurídica. $\mathrm{O}$ voto vencedor, entretanto, ponderou que o dever de indenizar poderia surgir de outros fundamentos, mormente a teoria geral da responsabilidade civil, que admite a reparação dos danos reflexos. Nesse sentido, o extrato do voto vencedor, da lavra do Ministro Luis Felipe Salomão.

O Juízo de primeira instância julgou procedentes os pedidos, condenando a ré a pagar, a título de indenização por danos materiais, o valor de R \$ 9.572,20 (nove mil, quinhentos e setenta e dois reais e vinte centavos), e à título de danos morais o valor equivalente à 25 (vinte e cinco) salários mínimos. [...]

Assim, embora o e. relator tenha afastado a legitimidade ativa da parte em virtude do malferimento do art. 17, CDC, deve-se analisar se estão presentes ou não, consoante o narrado pela autora, os pressupostos da responsabilidade civil, como a seguir será exposto. [...] Ou seja, como causa de pedir e fundamentação jurídica, a autora invocou, além do Código de Defesa do Consumidor, também o Código Civil e a teoria geral da responsabilidade civil.

3.2. Nesse passo, mister observar, primeiramente, que foi concluído um contrato de transporte entre o preposto vinculado a autora, com passagens adquiridas por esta, e a Companhia Aérea, com o objetivo de trazer ao Brasil as partituras necessárias à realização do evento organizado pela autora. Por conseguinte, dos fatos acolhidos como incontroversos pelo Tribunal de origem, exsurge que o contrato de transporte, diante das peculiaridades do caso,configura, na realidade, também uma estipulação em favor de terceiro, ou seja, em favor da Produtora de Eventos, que é, em última análise, a beneficiária do transporte das partituras e, conseqüentemente, a pessoa lesada pelo suscitado adimplemento defeituoso do contrato. [...] 
4. Ainda que assim não fosse, restaria legitimada a autora a propor ação em virtude da responsabilidade extrajudicial da ré pelos danos, em ricochete, ocasionados à autora em virtude daqueles gerados ao maestro pelo extravio de suas bagagens, com o qual possuía uma relação de dependência/subordinação. [...]

Destarte, como a autora, na causa de pedir, refere-se ao fato ilícito, dano, nexo causal e culpa da ré, mister também que a análise do caso seja realizada, do ponto de vista jurídico, com base nessa perspectiva do dano em ricochete, notadamente a análise da legitimidade ativa, mera condição da ação.

5. Destarte, como o acórdão apreciou a causa apenas aplicando o art. 17, CDC, malferindo o dispositivo legal, o que, como examinado, por si só, no caso concreto, não implica em ilegitimidade passiva da autora, penso que a melhor solução para a hipótese é acolher em parte o recurso da ré, apenas para cassar o acórdão, permitindo que novo julgamento seja realizado, apreciando-se todos os ângulos da questão, notadamente o pedido com base na teoria geral da responsabilidade civil.

Interessante notar que o magistrado relator calcou o seu entendimento, após ter afastado a incidência do artigo 17 do Código de Defesa do Consumidor à espécie, em dois fundamentos jurídicos principais: os danos reflexos e a modalidade de contrato em favor de terceiro. $\mathrm{O}$ contrato em favor de terceiro também é um dos fundamentos mais utilizados para respaldar a já citada hipótese da ação direta da vítima contra a seguradora, em casos em que esta injustificadamente não paga a indenização contratada pelo segurado causador do acidente.

Em relação a esse exemplo, Teresa Negreiros (2002, p. 226) afirma que a função social do contrato seria um argumento mais apropriado, pois a estipulação em favor de terceiro "[...] seria uma tese compatível com uma concepção voluntarista [...]”, distanciando-se da nova principiologia contratual. Assim, verifica-se que a função social do contrato também poderia, quiçá, ser utilizada como fundamento para o voto do Ministro relator, demonstrando, uma vez mais, as ricas relações entre os danos reflexos e a função social do contrato, bem como a possibilidade desta para figurar como um dos critérios para fixar algumas espécies de dano moral 
definitivamente dentro da moldura dos danos indenizáveis em nosso ordenamento.

\section{Conclusões}

O presente trabalho intentou demonstrar, a partir de uma definição clara da modelagem jurídica do dano reflexo ou por ricochete, algumas possibilidades de aplicação dessa categoria jurídica no direito pátrio, bem como evidenciar as conexões sistemáticas existentes com uma parte do conteúdo eficacional do princípio da função social do contrato.

Por intermédio do estudo do atual estágio da aplicação jurisprudencial do artigo 948 do Código Civil, pode-se verificar a amplitude indenizatória do chamado "caso clássico", assim denominado por ser observado em todos os ordenamentos jurídicos consultados.

Após a apreensão dos parâmetros indenizatórios utilizados no direito brasileiro em relação aos danos reflexos ou por ricochete, por meio da hipótese jurisprudencial mais observada (caso clássico), passou-se a verificar a possibilidade de se indenizar, no direito estrangeiro e no direito nacional, outras hipóteses de danos reflexos ou por ricochete.

Verificou-se que a flexibilização do princípio da relatividade dos efeitos contratuais, principalmente causados pela incidência do principio da função social dos contratos, fornecia um rico campo de estudo para novos exemplos de danos reflexos ou por ricochete.

Dentro do referido campo de estudo, realizou-se divisão sistemática de duas possíveis manifestações da estrutura triangular dos danos reflexos ou por ricochete, relacionadas com a eficácia dos efeitos contratuais estendida a terceiros. Notou-se que os danos reflexos podiam ser observados em ambas as manifestações do princípio da função social dos contratos, bem como ficou evidenciado que não era em todos os casos em que os efeitos contratuais se estendiam a terceiros que os danos reflexos seriam notados, conforme demonstrado pela teoria do terceiro cúmplice.

Por fim, concluiu-se que a conexão entre a aplicação do princípio da função social do contrato e os danos reflexos ou por ricochete mostrou-se 
extremamente rica, podendo, inclusive fixar o princípio da função social do contrato como um dos critérios de inclusão de algumas hipóteses de dano reflexos ou por ricochete dentro da moldura dos danos indenizáveis no ordenamento jurídico brasileiro.

\section{Referências}

AZEVEDO, Antonio Junqueira. Princípios do novo direito contratual e desregulamentação do mercado. Direito de exclusividade nas relações contratuais de fornecimento. Função social do contrato e responsabilidade aquiliana de terceiro que contribui para o inadimplemento contratual: autonomia da vontade, o princípio res inter alios acta, função social do contrato e a interferência alheia na execução dos negócios jurídicos. Revista dos Tribunais, São Paulo, v. 750, p. 113120, abr. 1998.

BRASIL. Superior Tribunal de Justiça. Recurso Especial n. 753.512 RJ. Recorrente: Compagnie Nationale Air France. Recorrido: Dell'arte Promoções Artísticas LTDA. Relator para acórdão: Min. Luis Felipe Salomão, julgado em 2 de março de 2010.

CAVALIERI FILHO, Sérgio. Programa de responsabilidade civil. 9. ed. São Paulo: Atlas, 2010.

GAMARRA, Jorge. Tratado de derecho civil uruguayo. Montevidéo: Fundacion de La Cultura Universitária, 2000. 19 v.

GERALDES, António Santos Abrantes. Temas de responsabilidade civil: Indemnização dos Danos Reflexos. 2. ed. Coimbra: Almedina, 2007. 2 v.

KFOURI NETO, Miguel. Responsabilidade civil do médico. 6. ed. São Paulo: Saraiva, 2007.

LE TOURNEAU, Philippe; CADIET, Loic. Droit de la responsabilité. Paris: Dalloz, 1998. 
MARTINS-COSTA, Judith. Novas reflexões sobre o princípio da função social dos contratos. Estudos de Direito do Consumidor, Coimbra, v. 7, p. 49-109, 2005.

MONTENEGRO, Antonio Lindbergh C. Ressarcimento de danos. 8. ed. Rio de Janeiro: Lumen Juris, 2005.

NEGREIROS, Teresa. Teoria do contrato: novos paradigmas. Rio de Janeiro: Renovar, 2002.

NORONHA, Fernando. Direito das obrigações: fundamentos do direito das obrigações: introdução à responsabilidade civil. São Paulo: Saraiva, 2003. $1 \mathrm{v}$.

PORTO, Mario Moacyr. Dano por ricochete. Revista Ajuris, Porto Alegre, n. 50, p. 51-56, set. 1996.

RODRIGUES JÚNIOR, Otávio Luiz. A doutrina do terceiro cúmplice: autonomia da vontade, o princípio res inter alios acta, função social do contrato e a interferência alheia na execução dos negócios jurídicos. Revista dos Tribunais, São Paulo, v. 821, n. 93, p. 80-98, mar. 2004. SANSEVERINO, Paulo de Tarso Viera. Princípio da reparação integral. São Paulo: Saraiva, 2010.

SCHIAVI, Mauro. Dano moral reflexo ou ricochete decorrente da relação de trabalho. Ltr: Legislação do Trabalho: suplemento trabalhista, São Paulo, v. 44, n. 43, p.213-215, 2008.

SILVA, Luiz Renato Ferreira da. Da legitimidade para postular indenização por danos morais. Revista Ajuris, Porto Alegre, v. 24, n. 69, p.192-193, jul. 1997.

VINEY, Geneviéve; JOURDAIN, Patrice. Traité de droit civil: les conditions de la responsabilité. 3. ed. Paris: L.g.d.j, 2006. 